\title{
FLOCCULATION, REINFORCEMENT, AND GLASS TRANSITION EFFECTS IN SILICA-FILLED STYRENE-BUTADIENE RUBBER
}

\author{
C. G. Robertson, ${ }^{1, *}$ C. J. Lin, ${ }^{1}$ R. B. Bogoslovov, ${ }^{2}$ M. Rackaitis, ${ }^{1}$ P. Sadhukhan, ${ }^{1}$ J. D. Quinn,${ }^{1}$ \\ C. M. ROLAND ${ }^{2}$ \\ ${ }^{1}$ BRIDGESTONE AMERICAS, CENTER FOR RESEARCH AND TECHNOLOGY, \\ 1200 FiRESTONE PARKWAY, AKRON, OH 44317-0001 \\ ${ }^{2}$ NAVAl Research LABORATORY, CHEMISTRY Division, CODE 6120, WASHINGTON, DC 20375-5342
}

RUBBER CHEMISTRY AND TECHNOLOGY, Vol. 84, No. 4, pp. 507-519 (2011)

\begin{abstract}
The introduction of silanes to improve processability and properties of silica-reinforced rubber compounds is critical to the successful commercial use of silica as a filler in tires and other applications. The use of silanes to promote polymer-filler interactions is expected to limit the development of a percolated filler network and may also affect the mobility of polymer chains near the particles. Styrene-butadiene rubber (SBR) was reinforced with silica particles at a filler volume fraction of 0.19 , and various levels of filler-filler shielding agent (n-octyltriethoxysilane) and polymerfiller coupling agent (3-mercaptopropyltrimethoxysilane) were incorporated. Both types of silane inhibited the filler flocculation process during annealing the uncured rubber materials, thus reducing the magnitude of the Payne effect. In contrast to the significant reinforcement effects noted in the strain-dependent shear modulus, the bulk modulus from hydrostatic compression was largely unaltered by the silanes. Addition of polymer-filler linkages using the coupling agent yielded bound rubber values up to $71 \%$; however, this bound rubber exhibited glass transition behavior which was similar to the bulk SBR response, as determined by calorimetry and viscoelastic testing. Modifying the polymer-filler interface had a strong effect on the nature of the filler network, but it had very little influence on the segmental dynamics of polymer chains proximate to filler particles. [doi:10.5254/1.3601885]
\end{abstract}

\section{INTRODUCTION}

Adding small fillers to elastomers in tire tread compounds can provide improvements in many performance properties. ${ }^{1}$ However, these particles can aggregate within the polymer to form filler networks which undergo hysteretic break-up at small strains (Payne effect), ${ }^{2-6}$ thus leading to undesirable reductions in the fuel economy of tires. In the case of silica as a reinforcing filler, silanes can be incorporated into rubber formulations to lessen the filler-filler contacts and reduce the loss tangent $\left(\tan \delta=\mathrm{G}^{\prime \prime} / \mathrm{G}^{\prime}\right)$ in the final vulcanizate. ${ }^{7-10}$ Silanes can also improve the processability of silica-filled rubber in the uncured state. ${ }^{11,12}$

Much of the filler network develops post-mixing when the rubber is annealed at elevated temperatures (e.g., during the early part of the cure process before the polymer network is established). Böhm and Nguyen ${ }^{13}$ were the first to highlight this feature, and more details about this flocculation phenomenon were revealed in later papers. ${ }^{8,9,14,15}$ In particular, introducing various silanes, which modify the surface of the silica for better compatibility with the polymer or create chemical links between the polymer backbone and the silica particles, can greatly suppress the filler flocculation process. ${ }^{8,9}$

The nature of the polymer-silica interface, as altered by silanes, may also influence the molecular mobility of the polymer chains near the filler. The effects of nanoconfinement, free surfaces, and interaction with particles on the glass transition of polymers have been reviewed in recent years with no general consensus revealed. ${ }^{16-18}$ There are observations that the segmental relaxation ( $\alpha$-relaxation) and glass transition temperature $\left(\mathrm{T}_{\mathrm{g}}\right)$ are not significantly affected by the presence of filler, despite significant levels of "bound" polymer from chemically modified polymer-filler interfaces and from well dispersed particles with high surface area. ${ }^{19-24}$ On the other hand, there are other reports which show that the filler can have a significant influence on 
the glass transition dynamics. ${ }^{25-31}$ In particular, the research of Tsagaropoulos and Eisenberg ${ }^{25,26}$ is often cited as support for the existence of severely retarded segmental motion of the polymer near the surfaces of small particles (glassy polymer shell). They observed a second $\tan \delta$ peak in viscoelastic data for various nanofilled uncrosslinked polymers which was $60-100{ }^{\circ} \mathrm{C}$ above the main viscoelastic glass transition of the polymer, and this was attributed to the $\mathrm{T}_{\mathrm{g}}$ of the polymer layer surrounding the particles. However, it was previously suggested ${ }^{17,21,32}$ and later conclusively demonstrated ${ }^{33}$ that the high temperature viscoelastic response was a flow-related phenomenon rather than the glass transition of a mobility-restricted polymer shell. Numerous studies have employed nuclear magnetic resonance (NMR) relaxation experiments to evaluate the effect of filler particles on polymer dynamics, and the results of this research are summarized elsewhere. ${ }^{17}$ Some of these NMR investigations reported retarded local relaxation of the polymer near the filler. ${ }^{34-40}$ It is possible that these conclusions may be the product of ambiguous data fitting rather than reflecting real modification of polymer dynamics due to the filler. ${ }^{17}$ It is evident that further research in this area is necessary to clarify the situation.

In this investigation, the influence of silanes on the filler network formation process and the glass transition behavior of silica-filled styrene-butadiene rubber (SBR) is examined. Filler reinforcement in hydrostatic compression deformation in comparison to oscillatory shear is also studied for these materials. The use of $n$-octyltriethoxysilane (OTES) is used to reduce the polarity of the silica surfaces in order to lessen filler agglomeration and to encourage better compatibilization of polymer and filler. Chemical bonds between SBR and silica surfaces are introduced using 3-mercaptopropyltrimethoxysilane (MPTMS) to further promote polymer-filler versus filler-filler interactions. The importance of these interfacial modifications is considered for the nanometer-scale local segmental dynamics of polymer chains near filler as well as larger scale filler network and reinforcement features of the silica-filled rubber compounds.

\section{EXPERIMENTAL DETAILS}

The polymer used was a styrene-butadiene statistical copolymer (SBR) with $\mathrm{M}_{\mathrm{w}}$ $=261 \mathrm{~kg} / \mathrm{mol}, \mathrm{M}_{\mathrm{w}} / \mathrm{M}_{\mathrm{n}}=2.3$, and $23.8 \mathrm{wt}$. \% styrene. The 1,4-cis/1,4-trans $/ 1,2$-vinyl microstructure for the anionic polymerization of the butadiene is $35 \% / 52 \% / 13 \%$ for this solution (lithium) SBR. The glass transition temperature is $-66{ }^{\circ} \mathrm{C}$ and the polymer Mooney viscosity $\left(\mathrm{ML}_{1+4} ; 100{ }^{\circ} \mathrm{C}\right)$ is 55 for this SBR. The silica filler was HiSil 190 from PPG Industries, Inc. which has a specific surface area of $\sim 200 \mathrm{~m}^{2} / \mathrm{g}$, and this particular grade of silica was extensively characterized by Schaefer et al. ${ }^{41}$ Simple compounds containing SBR (100 phr), silica (50 phr), antioxidant (1 phr), and silane (various concentrations) were formed using a Brabender internal mixer $\left(60\right.$ cc capacity) using a mixing speed of $50 \mathrm{rpm}$ and an initial temperature of $110{ }^{\circ} \mathrm{C}$. The term phr represents parts per hundred rubber in weight. After 4 min of mixing, the silane (OTES or MPTMS) was added, if present in the formulation. The total mixing time was $7 \mathrm{~min}$, and the drop temperature was $\sim 160{ }^{\circ} \mathrm{C}$. Curatives were not added to the compounds. In selected cases, the rubber compounds were annealed for $15 \mathrm{~min}$ at $170{ }^{\circ} \mathrm{C}$ to provide the thermal history of a typical cure cycle.

For quantifying filler flocculation (Payne effect) and measuring viscosity, viscoelastic measurements were conducted in oscillatory shear mode using an Alpha Technologies RPA 2000 rheometer which has a serrated biconical testing geometry. A strain sweep was performed at $0.1 \mathrm{~Hz}$ and $60{ }^{\circ} \mathrm{C}$ from $0.3 \%$ to $100 \%$ strain in logarithmic increments for the as-mixed compounds, and an identical test was run on compounds which were previously annealed for $15 \mathrm{~min}$ at $170{ }^{\circ} \mathrm{C}$ in the rheometer. A TA Instruments ARES (with dual 200 and $2000 \mathrm{~g}$-cm force rebalance transducers) was used to make oscillatory shear measurements as a function of temperature to evaluate the effect of filler and silanes on the viscoelastic glass transition 
(segmental relaxation process). This testing employed a strain amplitude $(\gamma)$ of $0.25 \%$, a frequency of $10 \mathrm{~Hz}$, and a torsion rectangular sample geometry. The temperature was incrementally changed and equilibrated at each temperature before viscoelastic testing unlike the more usual nonisothermal temperature ramp experiment. The glass transition behavior of the materials was also investigated by differential scanning calorimetry (DSC) using a TA Instruments Q2000 by heating from $-120^{\circ} \mathrm{C}$ to $20^{\circ} \mathrm{C}$ at a heating rate of $10{ }^{\circ} \mathrm{C} / \mathrm{min}$.

Bound rubber was determined as the percentage of polymer which could not be extracted from an uncured compound after immersion in toluene solvent for 3 days at $23{ }^{\circ} \mathrm{C}$. Transmission electron microscopy (TEM) was performed on cryogenically microtomed sections of the uncured rubber compounds using a Philips CM12 instrument. Atomic force microscopy (AFM) measurements were performed using Agilent 5500 AFM in acoustic ac mode. Nanosensor Super Sharp Silicon ${ }^{\mathrm{TM}}$ tips with resonant frequency of $170 \mathrm{kHz}$ and nominal tip radius of curvature of $2 \mathrm{~nm}$ were used. Measurements were performed using an oscillation amplitude that was around $65-75 \%$ of free amplitude, and the typical scan rate was 1 line/s. The sample surfaces for AFM were prepared by cryomicrotome, yielding average surface roughness below $100 \mathrm{~nm}$ for the uncured rubbers.

In order to assess the bulk (hydrostatic) modulus and the thermal expansion coefficient, a Gnomix instrument ${ }^{42}$ was employed for pressure-volume-temperature testing. This apparatus uses a pressurizable dilatometer wherein the sample is surrounded by mercury in flexible bellows. Volume changes were determined for temperatures ranging from 20 to $100{ }^{\circ} \mathrm{C}$ at pressures from 0 to $200 \mathrm{MPa}$. The density of each sample was evaluated at ambient $T$ and $P$ using the buoyancy method to allow the measured volume changes to be converted to values of specific volume $(V)$. Before $P V T$ testing, the uncrosslinked rubber samples were first annealed for $15 \mathrm{~min}$ at $170{ }^{\circ} \mathrm{C}$.

\section{RESULTS AND DISCUSSION}

The effect of silanes on the viscoelastic properties, glass transition behavior, and pressurevolume-temperature response of silica-filled SBR was studied at a constant silica volume fraction $(\phi)$ of 0.19 . The structures of the two silanes which were used in the rubber compounds are illustrated in Figure 1. Reaction of silica with OTES during mixing coats the particles with C8 alkyl chains; this reduces the interparticle attractive forces and makes the silica surfaces more compatible with the polymer to encourage interactions between the polymer and the filler. ${ }^{43}$ Use of MPTMS produces similar results with the additional feature that this coupling agent has a

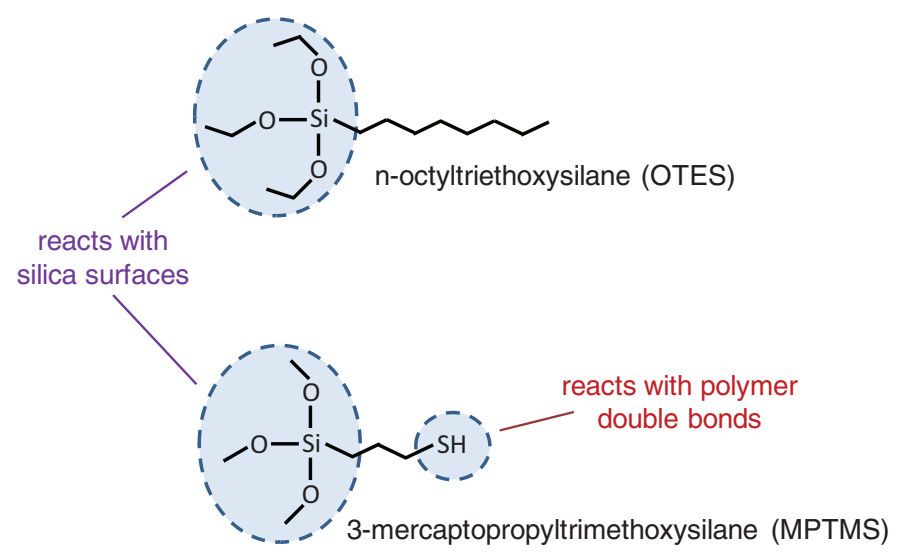

FIG. 1. - Illustration of the two silanes used in this study. 


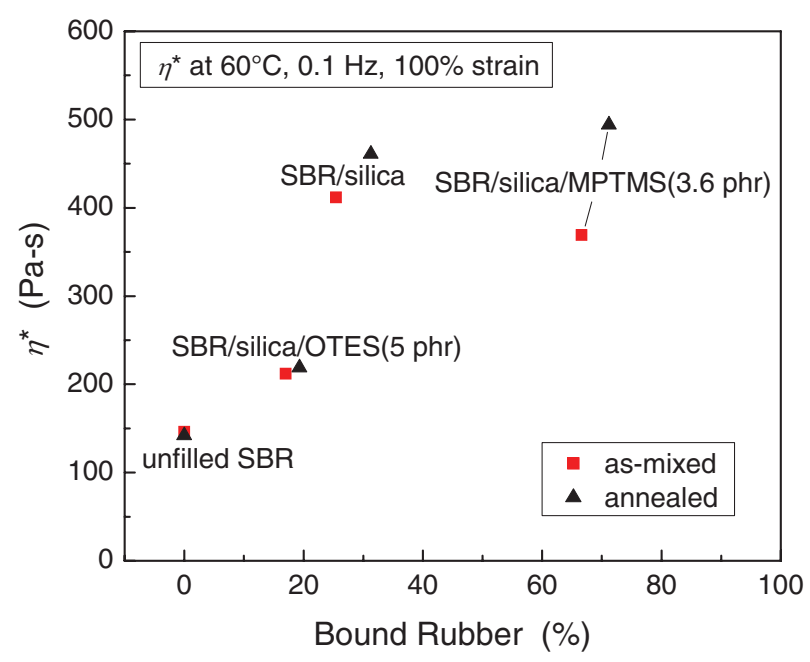

FIG. 2. - Dynamic viscosity vs bound rubber for the silica-filled SBR compounds.

mercaptan $(-\mathrm{S}-\mathrm{H})$ functional group which reacts with the double bonds on the polymer during high temperature mixing to form covalent bonds between polymer chains and the silica particles. Given the relative molecular weights of the two silanes, $5 \mathrm{phr}$ of OTES is equivalent to $3.6 \mathrm{phr}$ of MPTMS in terms of silane functionality.

The evidence of silane modification can be clearly noted from bound rubber and dynamic viscosity $\left(\eta^{*}\right)$ data in Figure 2. Use of 5 phr OTES greatly improved the processability (reduced viscosity) of the filled SBR by shielding filler-filler interactions without significantly affecting the amount of bound polymer. Incorporation of $3.6 \mathrm{phr}$ MPTMS coupling agent leads to very high values of bound rubber (67-71\%) with a comparable viscosity to the SBR/silica material due to the countervailing effects of reducing filler agglomeration and creating polymer-filler bonds. Lower concentrations of MPTMS can reduce the viscosity compared to the unmodified silica-filled SBR. The trends in Mooney viscosity data at $130{ }^{\circ} \mathrm{C}$ (not presented here) were similar to the $60{ }^{\circ} \mathrm{C}$ dynamic viscosity results (Figure 2).

A schematic of reinforcement features in filled elastomers is shown in Figure 3. Particles can provide hydrodynamic reinforcement to liquids and polymers, and this can be predicted by tools

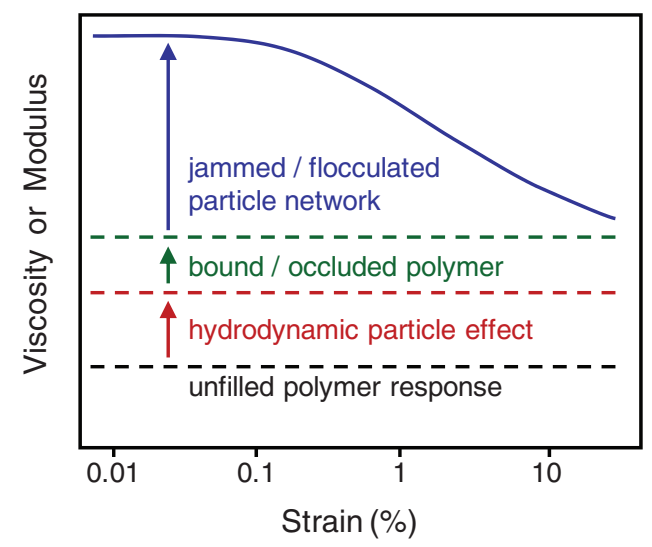

FIG. 3. - Illustration of reinforcement effects in particle-filled elastomers. 
such as the Guth-Gold expression, ${ }^{44,45}$ which is based on the Einstein viscosity equation with a term added to enable applicability to higher filler loadings:

$$
\frac{\eta}{\eta_{0}}=\frac{G}{G_{0}}=1+2.5 \phi+14.1 \phi^{2}
$$

In the above, the zero subscripts denote the values of viscosity $(\eta)$ and shear modulus $(G)$ for the unfilled polymer. Additional reinforcement from the bound/occluded rubber can arise if this material is shielded from stresses during flow and acts to increase the effective filler concentration. ${ }^{46}$ At filler concentrations above the filler network percolation threshold, there is considerable reinforcement above the hydrodynamic contribution due to the presence of a jammed filler network. However, this modulus enhancement is extremely sensitive to strain, and this network breakdown due to application of small strains is generally called the Payne effect ${ }^{2}$ or the Fletcher-Gent effect. ${ }^{47}$ It was recently revealed that the strain dependence noted in the unjamming process (Payne effect) of particle-filled rubber is strikingly similar to the influence of temperature on the glass transition of materials, ${ }^{4,48-51}$ because deformation can act as an effective temperature in jammed particle-filled materials and granular solids. ${ }^{48,49,52-55}$

It was mentioned earlier that much of the filler network develops during the filler flocculation process which can occur upon heating the compounds. ${ }^{13}$ For most practical rubber compounds, the majority of the filler network is formed as the material is heated during vulcanization, with the filler flocculation proceeding early in the cure cycle before polymer network gelation occurs. In this work, the difference between the storage modulus $\left(\mathrm{G}^{\prime}\right)$ at low $(0.3 \%)$ and high $(100 \%)$ strain amplitudes, $\Delta \mathrm{G}^{\prime}$, is used as an indicator of the strength of the filler network. Subtracting the $\Delta \mathrm{G}^{\prime}$ for as-mixed compounds from the $\Delta \mathrm{G}^{\prime}$ for the materials after heating for $15 \mathrm{~min}$ at $170{ }^{\circ} \mathrm{C}$ gives the $\delta \Delta \mathrm{G}^{\prime}$ which is a measure of the extent of filler flocculation which resulted from annealing the filled compounds. ${ }^{8}$ Examples of the strain dependence of $\mathrm{G}^{\prime}$ are presented in Figure 4 for as-mixed and annealed silica-filled SBR compounds (no curatives), and Table I summarizes the results for all of the samples. A large increase in the Payne effect was noted upon annealing the unmodified silica-filled SBR, and this silica flocculation was greatly suppressed by addition

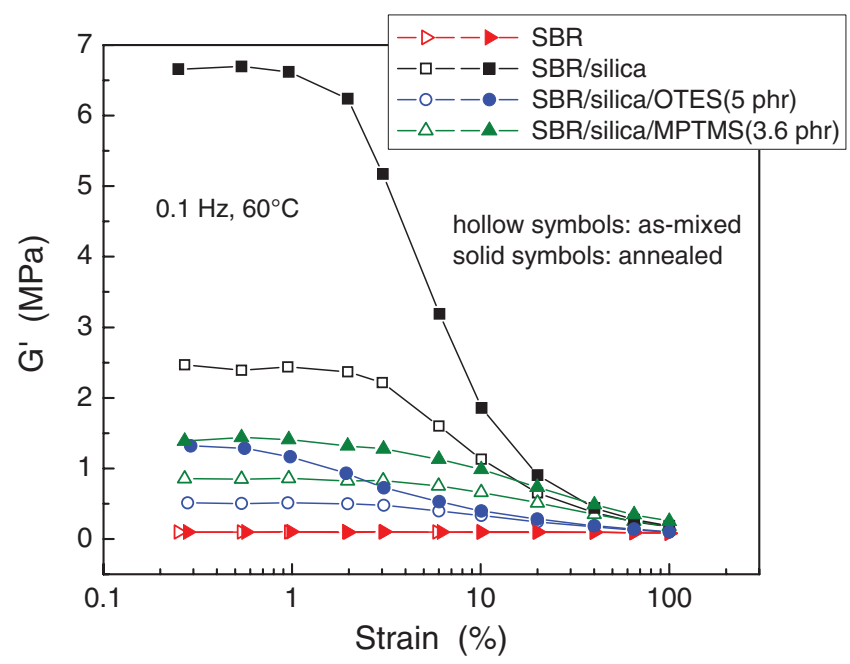

FIG. 4. - Strain amplitude dependence of dynamic storage modulus (Payne effect). Results are shown for the as-mixed compounds and for the materials after annealing for $15 \mathrm{~min}$ at $170{ }^{\circ} \mathrm{C}$ to allow filler flocculation. 
TABLE I

FILLER FLOCCULATION DATA FOR SBR COMPOUNDS

\begin{tabular}{lcccccc}
\hline $\begin{array}{l}\text { Silica } \\
\text { amount } \\
(\mathrm{phr})\end{array}$ & $\begin{array}{c}\text { Filler } \\
\text { volume } \\
\text { fraction }\end{array}$ & $\begin{array}{c}\text { Silane } \\
\text { additive }\end{array}$ & $\begin{array}{c}\text { Additive } \\
\text { amount } \\
(\mathrm{phr})\end{array}$ & $\begin{array}{c}\Delta \mathrm{G}^{\prime} \\
\text { as-mixed } \\
(\mathrm{MPa})\end{array}$ & $\begin{array}{c}\Delta \mathrm{G}^{\prime} \\
\text { annealed } \\
(\mathrm{MPa})\end{array}$ & $\begin{array}{c}\delta \Delta \mathrm{G}^{\prime} \\
(\mathrm{MPa})\end{array}$ \\
\hline 0 & 0 & None & - & 0.01 & 0.02 & 0.01 \\
50 & 0.189 & None & - & 2.30 & 6.47 & 4.17 \\
50 & 0.188 & OTES & 1 & 2.01 & 5.17 & 3.16 \\
50 & 0.185 & OTES & 2.5 & 1.06 & 3.25 & 2.19 \\
50 & 0.182 & OTES & 5 & 0.41 & 1.21 & 0.80 \\
50 & 0.188 & MPTMS & 0.7 & 1.56 & 3.97 & 2.42 \\
50 & 0.187 & MPTMS & 1.8 & 1.10 & 2.19 & 1.09 \\
50 & 0.184 & MPTMS & 3.6 & 0.67 & 1.13 & 0.46 \\
\hline
\end{tabular}

of both OTES and MPTMS, with the latter silane demonstrating better effectiveness (Figure 5). Inhibiting filler flocculation and reducing the magnitude of the hysteretic Payne effect is one of the major advantages of using silanes in silica-filled rubber.

Viscoelastic behavior is extremely sensitive to the structure of the filler network in particlereinforced polymers, and the strain-dependence of dynamic mechanical response after complex deformation histories can reveal details of the heterogeneity and kinetics of network break-up and recovery. ${ }^{48-50,56-60}$ When the particles are electrically conductive (e.g., carbon black), electrical resistance testing is another useful method to study the structure of the percolated filler network. ${ }^{61-64}$ With the exception of transmission electron microtomography, ${ }^{65,66}$ it is difficult to observe differences in the three-dimensional nature of jammed particle networks using microscopy. For example, the unmodified silica-filled SBR and the compound with $3.6 \mathrm{phr}$ MPTMS added have very different extents of filler networking based on $\mathrm{G}^{\prime}$ versus strain amplitude data (Figure 4), yet TEM images of these two distinct compounds are quite similar as demonstrated in Figure 6. Although AFM is also unable to clearly reveal differences in the filler networks for

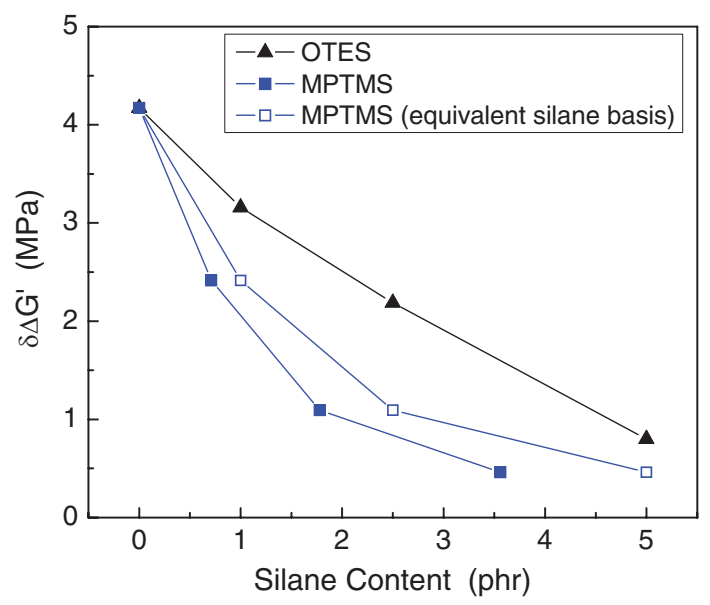

FIG. 5. - Extent of filler flocculation $\left(\delta \Delta \mathrm{G}^{\prime}\right)$ vs silane content. The data for MPTMS are plotted vs the actual phr as well as a function of the adjusted phr to allow comparison with OTES on an equivalent silane functionality basis. 

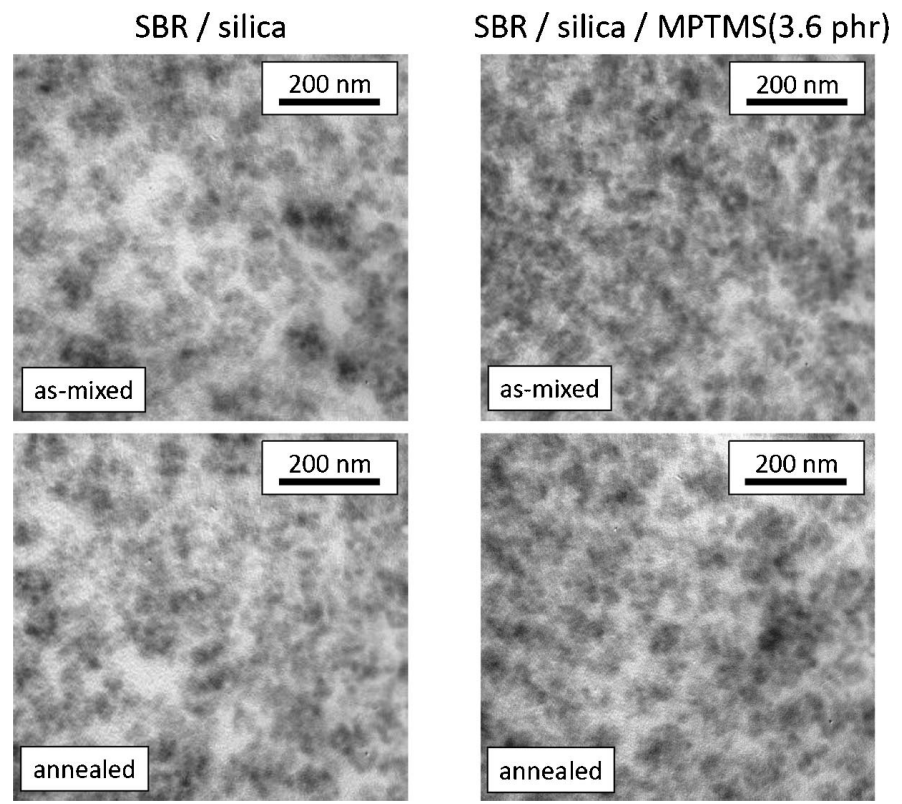

FIG. 6. - TEM results for the indicated samples in the as-mixed state and after annealing at $170{ }^{\circ} \mathrm{C}$ for $15 \mathrm{~min}$.

the materials studied here, the attachment of polymer to filler is noted in the rubber response to the AFM tapping deformation. The addition of the polymer-filler coupling agent (MPTMS) produced AFM results with $73 \%$ of the material exhibiting hardness in the intermediate region from 10 to $20^{\circ}$ phase difference in clear contrast to just $13 \%$ for the silica-filled SBR without silane (Figure 7).

SBR / silica

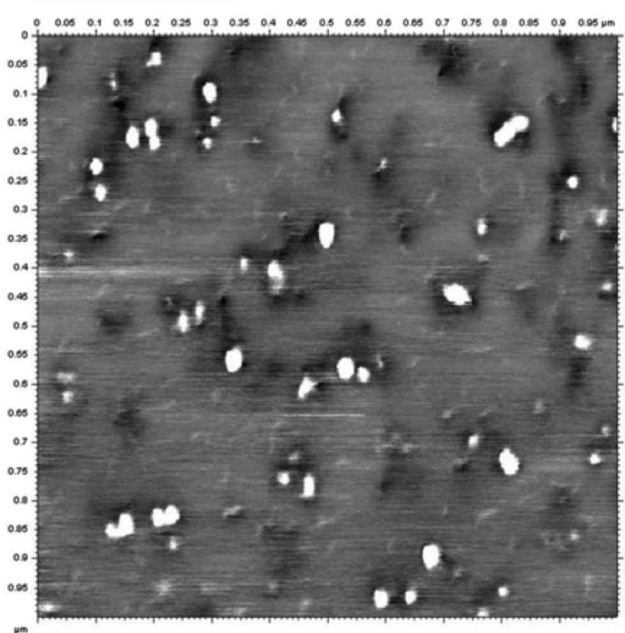

SBR / silica / MPTMS(3.6 phr)

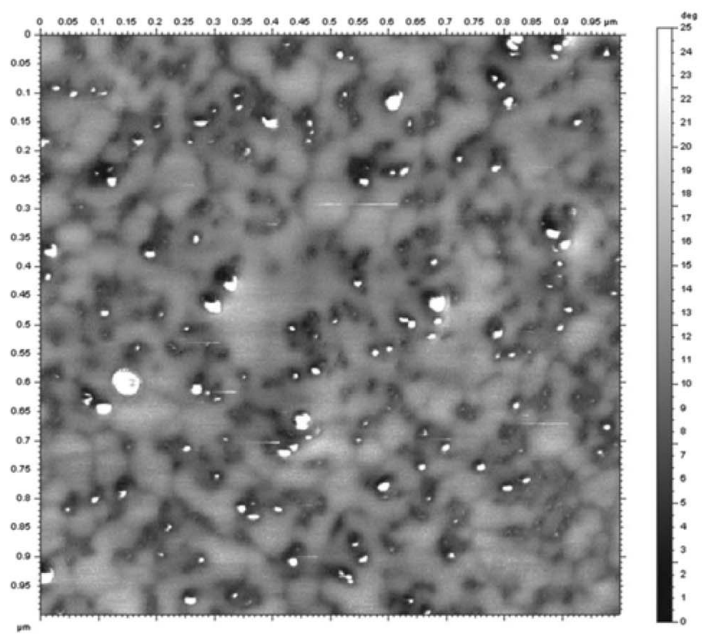

FIG. 7. - AFM images of $1 \mu \mathrm{m} \times 1 \mu \mathrm{m}$ area for SBR filled with silica at 0.19 filler volume fraction, both with and without MPTMS coupling agent. The micrographs were obtained in tapping mode and are phase contrast images, with harder regions appearing lighter. The phase contrast scale $\left(0^{\circ}-25^{\circ}\right)$ which is shown applies to both micrographs.

Samples were annealed for $15 \mathrm{~min}$ at $170^{\circ} \mathrm{C}$ before analysis. 
TABLE II

RESUlts From PrESSURE-VOLUME-TEMPERATURE TESTING

\begin{tabular}{lccccc}
\hline & \multicolumn{2}{c}{ Total volume } & & \multicolumn{2}{c}{ Polymer volume } \\
\cline { 2 - 3 } & $K(\mathrm{GPa})$ & $\alpha \times 10^{4}\left({ }^{\circ} \mathrm{C}^{-1}\right)$ & & $K(\mathrm{GPa})$ & $\alpha \times 10^{4}\left({ }^{\circ} \mathrm{C}^{-1}\right)$ \\
\hline SBR & 1.77 & 6.54 & & 1.77 & 6.54 \\
SBR/silica & 2.13 & 5.65 & & 1.82 & 6.61 \\
SBR/silica/OTES (5 phr) & 2.08 & 5.75 & & 1.78 & 6.72 \\
SBR/silica/MPTMS (3.6 phr) & 2.20 & 5.43 & & 1.87 & 6.37 \\
\hline
\end{tabular}

Note:

$K$ was measured at $60{ }^{\circ} \mathrm{C} ; \alpha$ was determined at $P=0$ in $T$ range from 20 to $100{ }^{\circ} \mathrm{C}$.

Typical standard deviation $=3 \%$ for $K$; typical standard deviation $=2 \%$ for $\alpha$.

The pressure-volume-temperature $(P V T)$ behavior of the SBR compounds was also investigated in order to measure the bulk modulus $(K)$ and the thermal expansion coefficient $(\alpha)$ :

$$
\begin{gathered}
K=-V\left(\frac{\partial P}{\partial V}\right)_{T}, \\
\alpha=\frac{1}{V}\left(\frac{\partial V}{\partial T}\right)_{P} .
\end{gathered}
$$

As indicated in Table II, there was a modest increase in the bulk modulus and a small decrease in the thermal expansion coefficient for the samples containing silica relative to the unfilled SBR.

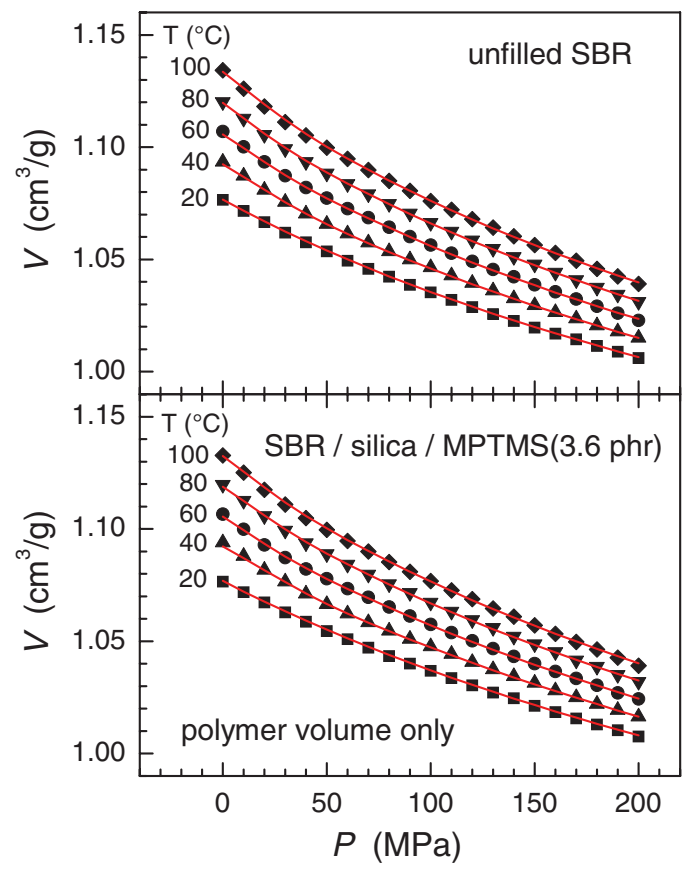

FIG. 8. - Pressure-volume-temperature response for SBR/silica/MPTMS (3.6 phr) with bound rubber $=71.2 \%$ compared to the behavior of unfilled SBR. The lines are fits to the Tait equation which is used to calculate $K$ and $\alpha$. 


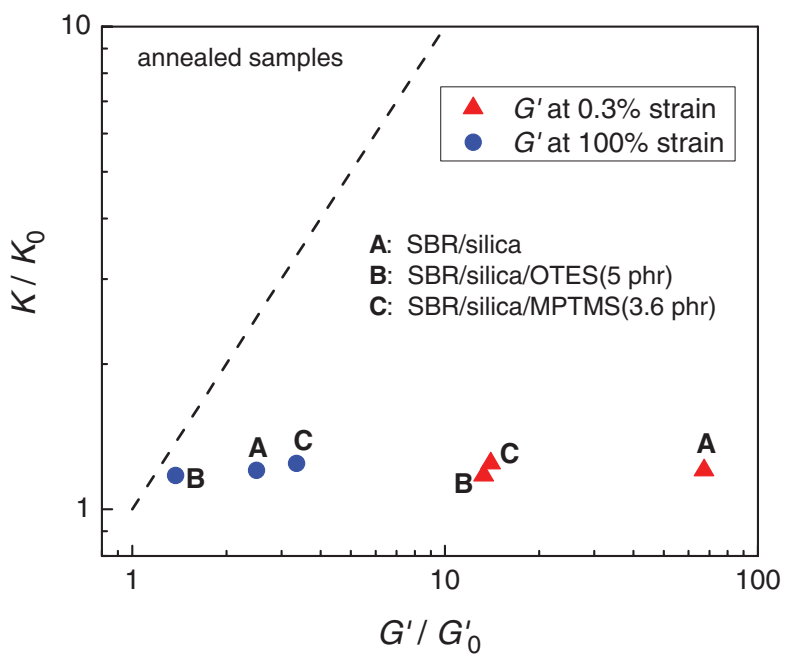

FIG. 9. - Reinforcement ratios for bulk modulus (determined using total volume) compared to dynamic shear modulus for the indicated compounds. The zero subscripts signify the values for the unfilled SBR. The dashed line represents equivalence of the reinforcement ratios.

The addition of the silanes did not significantly affect either $K$ or $\alpha$. The bulk modulus and thermal expansion coefficient of silica are orders of magnitude greater and lower, respectively, than the values for the polymer, ${ }^{67,68}$ so it is reasonable that the pressure- and temperature-induced volume changes reflect the response of the SBR only. Using only the polymer volume, the bulk modulus and thermal expansion values were essentially the same for the filled SBR compounds in comparison to the unfilled polymer (Table II). This is further emphasized in Figure 8 where the SBR/silica/MPTMS (3.6 phr) material displays nearly identical $P V T$ behavior to the neat polymer when only the polymer volume is accounted for in the filled compound. This supports the findings of a previous publication. ${ }^{69}$ It is certainly an underappreciated reality that, whereas the bound polymer and the presence of a jammed particle network play important roles in reinforcing an elastomer in shear or tension, the only effect of particles on the response to hydrostatic pressure is to lessen the concentration of deformable polymer. The much weaker particle reinforcement of $K$ compared to $\mathrm{G}^{\prime}$ for the silica-filled SBR compounds is highlighted in Figure 9.

There are different variables to control the reinforcement in filled polymers, such as the concentration and size (surface area) of the particles, and the nature of the polymer-filler interface. The presence of bound polymer and the formation of a flocculated/jammed filler network can enhance the modulus significantly beyond the hydrodynamic effect of particles, at least for shear and tensile modes of deformation. However, the same fillers do not reinforce the bulk modulus; the only effect of adding particle inclusions on the resistance to pressure is to decrease the amount of deformable polymer. For hydrostatic pressure there is no relative displacement between polymer chains and the particles which may explain the lack of filler reinforcement noted in volume deformation. It was suggested by Leaderman ${ }^{70}$ that intramolecular motions control the bulk modulus, while the shear modulus is governed by the intermolecular/intersegmental relaxations. Tabor $^{71}$ also argued that the bulk modulus arises from van der Waals interactions, whereas the extension of a rubber is predominantly an entropic process. Our results for filled SBR emphasize the difference in the molecular origins for shear and hydrostatic deformation, evident in the very different effects of particle reinforcement. 
TABLE III

BOUND RUBBER AND GLASS TRANSITION RESUlTS

\begin{tabular}{|c|c|c|c|c|c|c|}
\hline & \multicolumn{3}{|c|}{ As-mixed } & \multicolumn{3}{|c|}{ After annealing } \\
\hline & $\begin{array}{c}\text { Bound rubber } \\
(\%)\end{array}$ & $\begin{array}{l}\mathrm{T}_{\mathrm{g}} \\
\left({ }^{\circ} \mathrm{C}\right)\end{array}$ & $\begin{array}{c}\Delta \mathrm{C}_{\mathrm{p}}{ }^{a} \\
\left(\mathrm{~J} / \mathrm{g} /{ }^{\circ} \mathrm{C}\right)\end{array}$ & $\begin{array}{c}\text { Bound rubber } \\
(\%)\end{array}$ & $\begin{array}{c}\mathrm{T}_{\mathrm{g}} \\
\left({ }^{\circ} \mathrm{C}\right)\end{array}$ & $\begin{array}{c}\Delta \mathrm{C}_{\mathrm{p}}{ }^{a} \\
\left(\mathrm{~J} / \mathrm{g} /{ }^{\circ} \mathrm{C}\right)\end{array}$ \\
\hline SBR & 0 & -65.7 & 0.52 & 0 & -65.6 & 0.50 \\
\hline $\mathrm{SBR} /$ silica & 25.4 & -66.4 & 0.54 & 31.3 & -67.0 & 0.51 \\
\hline SBR/silica/OTES (5 phr) & 17.0 & -65.8 & 0.51 & 19.3 & -66.6 & 0.53 \\
\hline SBR/silica/MPTMS (3.6 phr) & 66.6 & -66.2 & 0.55 & 71.2 & -65.2 & 0.53 \\
\hline
\end{tabular}

${ }^{a}$ Based on polymer weight (not total weight).

In view of the controversial influence of filler particles on the glass transition which was summarized in the Introduction, the $\mathrm{T}_{\mathrm{g}}$ behavior of the filled SBRs was studied to probe this further. The results from DSC, detailed in Table III and plotted in Figure 10, show that the glass transition of the SBR did not change for any of the silica-reinforced SBR compounds relative to the unfilled polymer. Even though use of MPTMS introduced direct chemical bonding of polymer to silica with consequently high levels of bound rubber up to $71 \%$, the glass transition did not shift to higher temperatures, and the jump in heat capacity at $T_{g}\left(\Delta C_{p}\right)$ reflected the contribution of all of the polymer. To characterize the segmental relaxation process, the loss modulus $\left(\mathrm{G}^{\prime \prime}\right)$ versus the temperature peak is used rather than the $\tan \delta$ peak because the latter occurs at higher temperatures and has shape and magnitude which are unduly affected by the rubbery modulus. ${ }^{21}$ The dynamic mechanical results presented in Figure 11 corroborate the lack of filler-induced $\mathrm{T}_{\mathrm{g}}$ change noted by DSC. A review article in this area concludes that there are many such examples

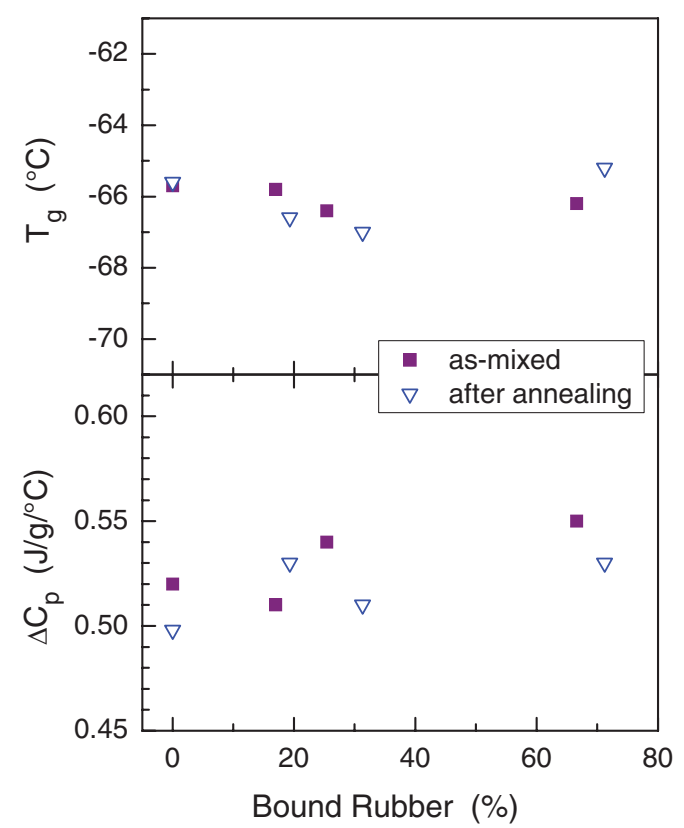

FIG. 10. - Effect of bound rubber on glass transition temperature and heat capacity jump at $T_{g}$ (polymer weight only) for the materials described in Table III. 


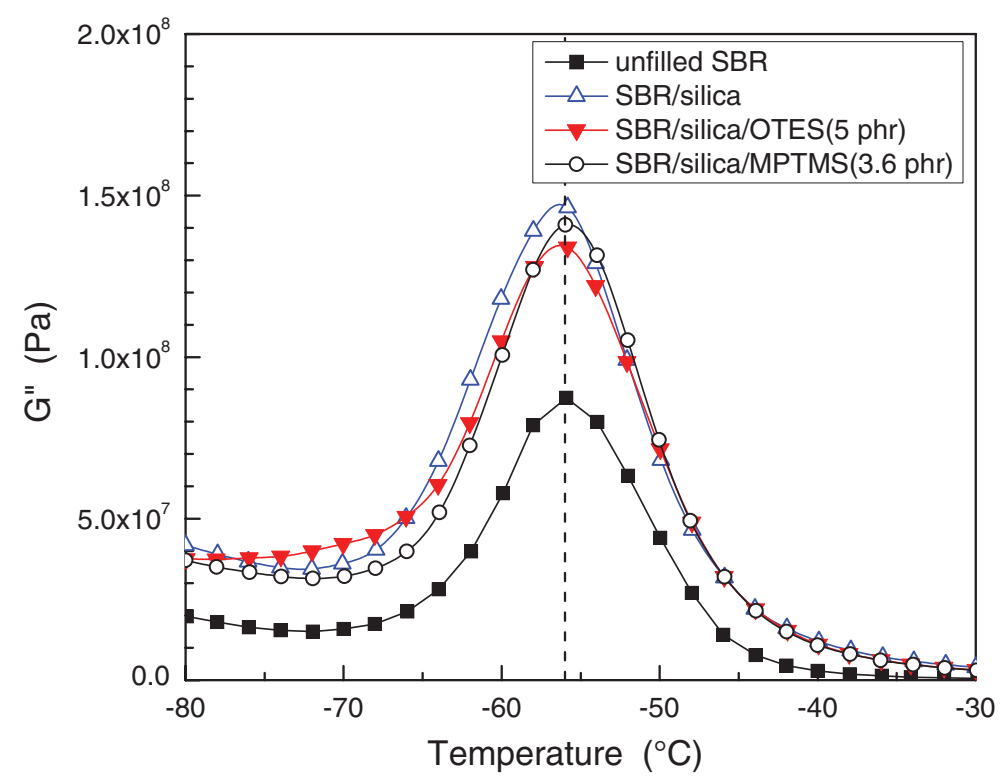

FIG. 11. - Segmental relaxation $\mathrm{G}^{\prime \prime}$ peaks in the glass transition region for the indicated compounds at $10 \mathrm{~Hz}$ and $0.25 \%$ strain.

of filled polymers with glass transitions and segmental dynamics which are not significantly affected by the presence of particles. ${ }^{17}$

\section{CONCLUSIONS}

Silane chemistry is a powerful tool to limit the development of a filler network and reduce the magnitude of the related hysteretic Payne effect in rubber compounds filled with silica particles. The use of both a filler-filler shielding ingredient (OTES) and a polymer-filler coupling agent (MPTMS) in silica-filled SBR with $\phi=0.19$ greatly suppressed the filler flocculation process. The chemical linking of polymer chains and silica particle surfaces by incorporation of MPTMS also produced very large bound rubber values up to $71 \%$, but this did not alter the glass transition behavior of the SBR. There was no evidence for reduced segmental mobility of the polymer near the filler for any of the materials studied herein, and this suggests that recent efforts ${ }^{72,73}$ to connect glassy shell concepts with the nonlinear viscoelastic response (Payne effect) may not be applicable to these commercially important filled polymers. It was additionally discovered that polymer-filler and filler-filler interactions play essentially no role in the reinforcement of bulk modulus from hydrostatic compression experiments unlike the large impact of these interactions on dynamic shear response.

\section{ACKNOWLEDGEMENTS}

Bridgestone Americas is acknowledged for approving the publication of this study. The work at NRL was supported by the Office of Naval Research.

\section{REFERENCES}

\footnotetext{
1 "Science and Technology of Rubber," J. E. Mark, B. Erman, and F. R. Eirich, Eds., 3rd ed., (Elsevier, London, 2005).
}

${ }^{2}$ A. R. Payne, J. Appl. Polym. Sci. 6, 57 (1962). 
${ }^{3}$ C. M. Roland, J. Rheol. 34, 25 (1990).

${ }^{4}$ C. G. Robertson and X. Wang, Phys. Rev. Lett. 95, 075703 (2005).

${ }^{5}$ G. Heinrich and M. Klüppel, Adv. Polym. Sci. 160, 1 (2002).

${ }^{6}$ M.-J. Wang, RubBer CHEM. TECHNOL. 72, 430 (1999).

${ }^{7}$ J. Ramier, C. Cauthier, L. Chazeau, L. Stelandre, and L. Guy, J. Polymer Sci., Part B: Polym. Phys. 45, 286 (2007).

${ }^{8}$ C. J. Lin, W. L. Hergenrother, E. Alexanian, and G. G. A Böhm, Rubber Chem. TeChnol. 75, 865 (2002).

${ }^{9}$ A. Scurati and C. J. Lin, RubBer Chem. TECHNOL. 79, 170 (2006).

${ }^{10}$ Y. P. Wu, Q. S. Zhao, S. H. Zhao, and L. Q. Zhang, J. Appl. Polym. Sci. 108, 112 (2008).

${ }^{11}$ K.-J. Kim and J. L. White, J. Ind. Eng. Chem. 7, 50 (2001).

${ }^{12}$ P. Sae-oui, C. Sirisinha, U. Thepsuwan, and K. Hatthapanit, Eur. Polym. J. 42, 479 (2006).

${ }^{13}$ G. G. A. Böhm and M. N. Nguyen, J. Appl. Polym. Sci. 55, 1041 (1995).

${ }^{14}$ G. A. Schwartz, S. Cerveny, A. J. Marzocca, M. Gerspacher, and L. Nikiel, Polymer 44, 7229 (2003).

${ }^{15}$ J. G. Meier and M. Klüppel, Macromol. Mater. Eng. 293, 12 (2008).

${ }^{16}$ M. Alcoutlabi and G. B. McKenna, J. Phys. Condens. Matter 17, R461 (2005).

${ }^{17}$ C. G. Robertson and C. M. Roland, RubBer ChEM. TEChNOL. 81, 506 (2008).

${ }^{18}$ S. Sills and R. M. Overney, “Applied Scanning Probe Methods III," B. Bhushan and H. Fuchs, Eds., (Springer-Verlag, Heidelberg, Germany, 2006), pp. 83-130.

${ }^{19}$ S. Vieweg, R. Unger, G. Heinrich, and E. Donth, J. Appl. Polym. Sci. 73, 495 (1999).

${ }^{20}$ J. G. I. Rodriguez, P. Carreira, A. Garcia-Diez, D. Hui, R. Artiaga, and L. M. Liz-Marzan, J. Therm Anal. Calorim. 87, 45 (2007).

${ }^{21}$ C. G. Robertson, C. J. Lin, M. Rackaitis, and C. M. Roland, Macromolecules 41,2727 (2008).

${ }^{22}$ R. B. Bogoslovov, C. M. Roland, A. R. Ellis, A. M. Randall, and C. G. Robertson, Macromolecules 41,1289 (2008).

${ }^{23}$ J. Fritzsche, M. Klüppel, and J. G. Meier, Kautsch. Gummi Kunstst. 62, 319 (2009).

${ }^{24}$ G. Kraus and J. T. Gruver, J. Polym. Sci., Part A-2 8, 571 (1970).

${ }^{25} \mathrm{G}$. Tsagaropoulos and A. Eisenberg, Macromolecules 28, 396 (1995).

${ }^{26}$ G. Tsagaropoulos and A. Eisenberg, Macromolecules 28, 6067 (1995).

${ }^{27}$ V. Arrighi, I. J. McEwen, H. Qian, and M. B. Serrano Prieto, Polymer 44, 6259 (2003).

${ }^{28}$ A. Bansai, H. C. Yang, C. Z. Li, R. C. Benicewicz, S. K. Kumar, and L. S. Schadler, J. Polym. Sci., Part B: Polym. Phys. 44, 2944 (2006).

${ }^{29}$ H. Oh and P. F. Green, Nature Mater. 8, 139 (2009).

${ }^{30}$ D. Fragiadakis, P. Pissis, and L. Bokobza, Polymer 46, 6001 (2005).

${ }^{31}$ S. Gagliardi, V. Arrighi, R. Ferguson, and M. T. F. Telling, Physica B 301, 110 (2001).

${ }^{32}$ S. Salaniwal, S. K. Kumar, and J. F. Douglas, Phys. Rev. Lett. 89, 258301 (2002).

${ }^{33}$ C. G. Robertson and M. Rackaitis, Macromolecules 44,1177 (2011).

${ }^{34}$ J. Berriot, F. Lequeux, L. Monnerie, H. Montes, D. Long, and P. Sotta, J. Non-Cryst. Solids 307-310, 719 (2002).

${ }^{35}$ J. C. Kenny, V. J. McBrierty, Z. Rigbi, and D. C. Douglass, Macromolecules 24, 436 (1991).

${ }^{36}$ S. Kaufman, W. P. Slichter, and D. D. Davis, J. Polym. Sci., Part A-2 9, 829 (1971).

${ }^{37}$ T. Nishi, J. Polym. Sci., Polym. Phys. Ed. 12, 685 (1974).

${ }^{38}$ H. Luchow, E. Breier, and W. Gronski, RubBer Chem. TeChNOL. 70, 747 (1997).

${ }^{39}$ N. Kida, M. Ito, F. Yatsuyanagi, and H. Kaido, J. Appl. Polym. Sci. 61, 1345 (1996).

${ }^{40}$ A. Papon, K. Saalwächter, K. Schäler, L. Guy, F. Lequeux, and H. Montes, Macromolecules 44, 913 (2011).

${ }^{41}$ D. W. Schaefer, C. Suryawanshi, P. Pakdel, J. Ilavsky, and P. R. Jemian, Physica A 314, 686 (2002).

${ }^{42}$ P. Zoller and D. J. Walsh, "Standard Pressure-Volume-Temperature Data for Polymers," (Technomic, Lancaster, PA, 1995).

${ }^{43}$ A. Scurati, W. L. Hergenrother, and C. J. Lin, J. Appl. Polym. Sci. 108, 1722 (2008). 
${ }^{44}$ E. Guth, J. Appl. Phys. 16, 20 (1945).

${ }^{45}$ D. J. Kohls and G. Beaucage, Curr. Opin. Solid State Mater. Sci. 6, 183 (2002).

${ }^{46}$ A. I. Medalia, Rubber Chem. TeChNOL. 45, 1171 (1972).

${ }^{47}$ W. P. Fletcher and A. N. Gent, Trans. Inst. Rubber Ind. 29, 266 (1953).

${ }^{48}$ X. Wang and C. G. Robertson, Phys. Rev. E 72, 031406 (2005).

${ }^{49}$ C. G. Robertson and X. Wang, Europhys. Lett. 76, 278 (2006).

${ }^{50}$ X. Wang and C. G. Robertson, Europhys. Lett. 79, 18001 (2007).

${ }^{51}$ C. G. Robertson, R. Bogoslovov, and C. M. Roland, Phys. Rev. E 75, 051403 (2007).

${ }^{52}$ G. D'Anna and G. Gremaud, Nature (London) 413, 407 (2001).

${ }^{53}$ I. K. Ono, C. S. O’Hern, S. A. Langer, A. J. Liu, and S. R. Nagel, Phys. Rev. Lett. 89, 095703 (2002).

${ }^{54}$ L. Berthier and J.-L. Barrat, J. Chem. Phys. 116, 6228 (2002).

${ }^{55}$ P. Sollich, F. Lequeux, P. Hebraud, and M. E. Cates, Phys. Rev. Lett. 78, 2020 (1997).

${ }^{56}$ M.-J. Wang, Kautsch. Gummi Kunstst. 51106 (1998).

${ }^{57}$ L. Chazeau, J. D. Brown, L. C. Yanyo, and S. S. Sternstein, Polym. Compos. 21, 202 (2000).

${ }^{58}$ Z. Zhu, T. Thompson, S.-Q. Wang, E. V. von Meerwall, and A. Halasa, Macromolecules 38, 8816 (2005).

${ }^{59}$ R. L. Warley, D. L. Feke, and I. Manas-Zloczower, J. Appl. Polym. Sci. 98, 1001 (2005).

${ }^{60}$ G. B. McKenna, T. Narita, and F. Lequeux, J. Rheol. 53, 489 (2009).

${ }^{61}$ L. Nikiel, M. Gerspacher, H. Yang, and C. P. O’Farrell, RubBer Chem. TeChnol. 74, 249 (2001).

${ }^{62}$ A. I. Medalia, RubBer Chem. TeChnOL. 59, 432 (1986).

${ }^{63}$ L. Karasek and M. Sumita, J. Mater. Sci. 31, 281 (1996).

${ }^{64}$ M. Klüppel, R. H. Schuster, and G. Heinrich, RubBER CHEM. TECHNOL. 70, 243 (1997).

${ }^{65}$ H. Jinnai, Y. Shinbori, T. Kitaoka, K. Akutagawa, N. Mashita, and T. Nishi, Macromolecules 40, 6758 (2007).

${ }^{66}$ K. Akutagawa, K. Yamaguchi, A. Yamamoto, H. Heguri, H. Jinnai, and Y. Shinbori, RubBer CHEM. TECHNOL. 81, 182 (2008).

${ }^{67}$ G. K. White, J. Appl. Phys. 6, 2070 (1973).

${ }^{68}$ L. Huang, L. Duffrene, and J. Kieffer, J. Non-Cryst. Solids 349, 1 (2004).

${ }^{69}$ C. G. Robertson, R. Bogoslovov, and C. M. Roland, RUBBER CHEM. TECHNOL. 82, 202 (2009).

${ }^{70}$ H. Leaderman, “Rheology, Vol. 2," F. R. Eirich, Ed., (Academic, New York, 1958).

${ }^{71}$ D. Tabor, Polymer 35, 2759 (1994).

${ }^{72}$ S. Merabia, P. Sotta, and D. R. Long, Macromolecules 41, 8252 (2008).

${ }^{73}$ H. Montes, F. Lequeux, and J. Berriot, Macromolecules 36, 8107 (2003).

[Paper 30, Presented at the Fall 176th Technical Meeting of the Rubber Division, ACS (Pittsburgh, PA), 13-15 October, 2009]

[Received April 27, 2011] 